\title{
Potencial alelopático de seis espécies do gênero Croton L. na germinação de alface e tomate
}

\author{
Giuliane Sampaio de Souza', Oriel Herrera Bonilla², Bruno Edson Chaves², \\ Eliseu Marlônio Pereira de Lucena ${ }^{2}$ \& Charles de Sousa Silva ${ }^{3}$
}

\author{
'Universidade Estadual do Ceará, Programa de Pós-Graduação em Recursos Naturais, Av. Dr. Silas Munguba, 1700, CEP 60740-903, \\ Campus do Itaperi, Fortaleza, Ceará. sampaio.giuliane@gmail.com. \\ 2Universidade Estadual do Ceará, Centro de Ciências da Saúde, Av. Dr. Silas Munguba, 1700, CEP 60740-903, Campus do Itaperi, \\ Fortaleza, Ceará. oriel.herrera@vece.br, brunoedch@gmail.com, eliseulucena@yahoo.com.br. \\ 3Universidade Regional do Cariri, Programa de Pós-Graduação em Bioprospecção Molecular, Rua Cel. Antônio Luis, 1161, CEP 63100-000 \\ Pimenta, Crato, Ceará. ag_charles@hotmail.com.
}

Recebido em 25.VI.2015

Aceito em 16.VI.2017

DOI 10.21826/2446-8231201772201

\begin{abstract}
RESUMO - O presente estudo objetivou avaliar a fitotoxidez e o potencial alelopático dos hidrolatos de Croton argyrophylloides Muell. Arg., C. blanchetianus Baill., C. jacobinensis Baill., C. nepetaefolius Kunth., C. sincorensis Mart. ex Muell. Arg. e C. zehntneri Pax. et. Hoffm. na germinação de diásporos de alface e tomate. Realizaram-se observações diárias e medição do teste-padrão de germinação (TPG), da primeira contagem ( $\left.1^{\mathrm{a}} \mathrm{C}\right)$ e índice de velocidade de germinação (IVG). A intensidade da atividade fitotoxica de cada espécie, variou em função da concentração, da espécie receptora e do fotoperíodo. C. argyrophylloides, C. blanchetianus e C. nepetaefolius apresentaram ação inibitória em todos os fotoperíodos. Foram observados alguns efeitos estimulantes para a C. sincorensis e C. argyrophylloides. No entanto, os resultados deste estudo fornecem indicações consistentes do potencial alelopático das espécies testadas.
\end{abstract}

Palavras-chave: fitotoxidez, hidrolato, Euphorbiaceae

\begin{abstract}
Allelopathic potential of six species of the genus Croton L. in the germination of lettuce and tomato. This study aimed to evaluate the phytotoxicity and allelopathic potential of hydrolats of Croton argyrophylloides Muell. Arg., C. blanchetianus Baill., C. jacobinensis Baill., C. nepetaefolius Kunth., C. sincorensis Mart. ex Muell. Arg. and C. zehntneri Pax. et. Hoffm. in the germination of diaspores of lettuce and tomato. There were daily observations and measurement of the standard test of germination (TSG), first count $\left(1^{\mathrm{a}} \mathrm{C}\right)$ and germination speed index (GSI). The intensity of the phytotoxic activity of each species varied according to concentration, species and photoperiod. C. argyrophylloides, C. blanchetianus, and C. nepetaefolius were inhibited in all photoperiods. Some stimulating effects were observed for C. sincorensis and C. argyrophylloides. Nevertheless, the results of this study provide consistent indications of the allelopathic potential of tested species.
\end{abstract}

Keywords: phytotoxicity, hydrolate, Euphorbiaceae

\section{INTRODUÇÃO}

Croton L. (Euphorbiaceae) é o quarto maior gênero de angiospermas em número de espécies no Brasil. Das 316 espécies ocorrentes no território nacional, podemos encontrar na Caatinga 62 espécies (Cordeiro et al. 2015) conhecidas por sua utilização na medicina popular (Borba $\&$ Macedo 2006). Plantas medicinais possuem efeito alelopático sobre sementes de espécies vegetais cultivadas e invasoras (Cruz et al. 2000). Os estudos dos efeitos alelopáticos e a identificação das plantas que o possuem é assunto de grande importância, tanto na utilização de cultivares agrícolas capazes de inibir plantas daninhas, quanto na determinação de práticas culturais e do manejo mais adequado (Carvalho et al. 1996).

Embora a maioria dos estudos com produtos medicinais alternativos tenha sido realizado com óleos essenciais, outros compostos podem ainda ser utilizados, como o hidrolato. Este é o subproduto resultante do processo de extração de óleo essencial por arraste a vapor (Lavabre 1993). Ele é rico em substâncias hidrofílicas (Lima et al. 2006) e retém muitas das propriedades terapêuticas da planta, sendo útil em preparados para a pele ou até para preparações de administração oral (Cunha et al. 2012).

O hidrolato de Baccharis trimera (Less.) DC. apresenta substâncias ativas com potencial para o controle de doenças em plantas, principalmente por sua atividade antibacteriana (Moura et al. 2014). O hidrolato da parte aérea de Brachiaria humidicola (Rendle) Schweick. provocou inibição na germinação de sementes de Stylosanthes Sw., Macrotyloma axillare (E. Mey.) Verdc., Desmodium ovalifolium Guill. \& Perr., e Lactuca sativa L. (Ribeiro et al. 2012). Enquanto que hidrolatos de quatro espécies de Croton mostraram-se úteis contra larvas de Aedes aegypti (Lima et al. 2006).

Estes estudos oferecem excelentes oportunidades para a descoberta de novos modelos de herbicidas naturais, 
que podem ser empregados em programas de biocontrole de pragas, sendo menos prejudiciais ao meio ambiente do que os herbicidas sintéticos aplicados atualmente nas culturas (Muller et al. 2007). Desta forma, esta pesquisa visa verificar efeitos fitotóxicos de hidrolatos de algumas espécies do gênero Croton na germinação de diásporos de alface e tomate em dois fotoperíodos; uma vez que para o gênero há carência de estudos relacionados a estes aspectos.

\section{MATERIAL E MÉTODOS}

\section{Material vegetal}

Foram coletadas $1.200 \mathrm{~g}$ (400 g na primeira coleta, 400 g na segunda coleta e $400 \mathrm{~g}$ na terceira coleta, as quais foram secas e misturadas antes da extração do hidrolato) de folhas verdes de plantas adultas de Croton L. (Quadro 1), mantidas em área experimental no Laboratório de Ecologia (LABOECO) da Universidade Estadual do

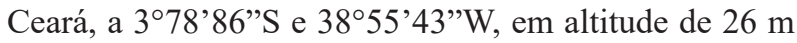
sob condições naturais do ambiente. As exsicatas estão depositadas no Herbário EAC, da Universidade Federal do Ceará.

As coletas ocorreram durante o período chuvoso, nos meses de abril, maio e junho com temperatura média de $26,9^{\circ} \mathrm{C}, 26,7^{\circ} \mathrm{C}$ e $26,9^{\circ} \mathrm{C}$ e pluviometria total de 266,9 $\mathrm{mm}, 257,1 \mathrm{~mm}$ e $56,0 \mathrm{~mm}$, respectivamente (INMET 2014), às 09h00min da manhã. Posteriormente submetidas ao processo de arraste por vapor de água sob pressão controlada (0-0,1 atm), isto é, destilação à vácuo, por um período de uma hora a extração dos óleos essenciais das espécies estudadas (AOAC 1995). A baixa pressão permite que a destilação seja realizada a temperaturas mais baixas, minimizando a degradação dos constituintes do óleo e do hidrolato que é fase aquosa condensada, ainda rica em constituintes aromáticos. Os hidrolatos foram separados da camada de óleo e armazenados em vidro âmbar coberto com papel alumínio e mantido a $4^{\circ} \mathrm{C} \pm 1$ por 24 horas. Para os testes de fitotoxidez os hidrolatos foram diluídos em água destilada, obtendo-se as concentrações de 50 e 100\%. Água destilada foi usada como controle ( $0 \%)$.

\section{Bioensaios de germinação}

Os diásporos de alface (frutos contendo uma semente) (037-Alface Crespa Grand Rapids -TBR - Lactuca sativa L., lote 28371A, pureza: 99,9\%, marca: ISLA PAK) e sementes de tomate (265-Tomate Rasteiro Rio Grande Lycopersicon esculentum Mill., lote 28398, pureza: 100,0\%, marca: ISLA PAK), foram tratadas com todos os hidrolatos de Croton spp. nas concentrações supracitadas, além do controle (água destilada).

A verificação do potencial alelopático dos hidrolatos, nas diversas concentrações, foi realizada por avaliação do teste-padrão de germinação (TPG), da primeira contagem $\left(1^{\mathrm{a}} \mathrm{C}\right)$ e do índice de velocidade de germinação (IVG) dos diásporos de alface e sementes de tomate.

Para o teste-padrão de germinação da alface e do tomate, foram testadas três concentrações (0, 50 e 100\% de hidrolato) com quatro repetições de 50 sementes cada, conforme as Regras para Análise de Sementes (Brasil 2009). Para cada repetição, 50 sementes foram colocadas em placas de Petri (9 $\mathrm{cm}$ de diâmetro), tendo como substrato duas folhas de papel-filtro, umedecidas com $3 \mathrm{~mL}$ da solução de cada concentração distribuídos pela placa. Em seguida, essas placas foram levadas para câmaras de germinação (tipo B.O.D.), com fotoperíodos distintos, objetivando avaliar o efeito da luz no potencial alelopático, uma de 12 horas de luz e outra de 14 h de luz, a $25^{\circ} \mathrm{C}$, e a percentagem de germinação avaliada diariamente durante seis dias. A cada dois dias as placas foram umedecidas com $2 \mathrm{~mL}$ de água destilada para evitar o ressecamento (Ferreira \& Aquila 2000). Considerouse germinadas as sementes que apresentarem protrusão radicular acima de $2 \mathrm{~mm}$ ou o seu tamanho ser no mínimo $50 \%$ do tamanho da semente. A primeira avaliação foi efetuada aos um e dois dias após semeadura (DAS), respectivamente para alface e tomate, e a avaliação final aos seis DAS. A fórmula utilizada para o cálculo da percentagem de germinação foi a descrita por Labouriau $\&$ Valadares (1976): $G_{\text {(plântulas dia) }}=(\mathrm{N} / \mathrm{A})$ x 100; Onde: $\mathrm{N}=$ número total de sementes germinadas; $\mathrm{A}=$ número total de sementes colocadas para germinar.

A $1^{\text {a }} \mathrm{C}$ foi determinada avaliando-se a percentagem de plântulas normais, obtidas por ocasião da primeira contagem (1 DAS para alface e 2 DAS para tomate) do TPG. Os resultados foram expressos em percentagem média de plântulas normais por lote.

O cálculo do IVG foi realizado de acordo com Vieira \& Carvalho (1994): IVG (plântulas dia) $=\AA_{1} / N_{1}+\AA_{2} / N_{2}+\ldots \AA_{n} / N_{n}$; Onde: å = número de plântulas germinadas na primeira, segunda, terceira e nas contagens subsequentes, até a última; $\mathrm{N}=$ número de dias da semeadura da primeira, segunda, terceira e nas contagens subsequentes, até a última.

O delineamento experimental adotado foi inteiramente casualizado, com três concentrações e quatro repetições

Quadro 1. Espécies de Croton avaliadas no presente estudo com seus respectivos nomes populares.

\begin{tabular}{llc}
\hline Nome científico & Nome popular & $N^{o}$ de exsicata \\
\hline Croton argyrophylloides Muell. Arg. & Marmeleiro prateado & 46719 \\
Croton blanchetianus Baill. & Marmeleiro preto & 46720 \\
Croton jacobinensis Baill. & Velame de orelha & 46715 \\
Croton nepetaefolius Kunth. & Marmeleiro sabiá & 46718 \\
Croton sincorensis Mart. ex Muell.Arg. & Marmeleiro branco & EAC \\
Croton zehntneri Pax. et. Hoffm. & Canela de cunhã & 46716 \\
\hline
\end{tabular}


de 50 sementes cada. Os dados foram submetidos a teste de normalidade Shapiro - Wilk, análise de variância e os valores médios comparados pelo teste de Tukey $(\mathrm{p}<0,05)$, utilizando o programa BioEstat 5.0.

\section{RESULTADOS E DISCUSSÃO}

\section{Primeira contagem do teste-padrão de germinação $\left(1^{\mathrm{a}} \mathrm{C}\right)$}

A germinação dos diásporos de alface teve início antes de $24 \mathrm{~h}$ em todas as concentrações. Para primeira contagem do teste-padrão de germinação $\left(1^{\mathrm{a}} \mathrm{C}\right)$ no fotoperíodo de $12 \mathrm{~h}$ de luz foi observado efeito inibitório apenas nos hidrolatos de $C$. argyrophylloides, C. blanchetianus, $C$. nepetaefolius e C. zehntneri. O C. nepetaefolius foi a espécie que apresentou o maior efeito inibitório para $1^{\mathrm{a}}$ $\mathrm{C}$, seguido por C. argyrophylloides (Tab. 1).

No fotoperíodo de $14 \mathrm{~h}$ de luz foi observado efeito inibitório para $1^{\text {a }} \mathrm{C}$ apenas nos hidrolatos de $C$. argyrophylloides, $C$. blanchetianus, $C$. jacobinensis e C. nepetaefolius. O C. nepetaefolius foi a espécie que apresentou o maior efeito inibitório em $24 \mathrm{~h}$ e o $C$. jacobinensis com menor efeito. O C. sincorensis foi a única espécie que apresentou efeito estimulante (Tab. 2). Cruz et al. (2000) afirmam que a alelopatia não tem efeito somente de inibição, mas também pode estimular a germinação, portanto, as espécies supracitadas possuem potencial alelopático.

Os componentes majoritários das espécies estudadas são monoterpenos e sesquiterpenos como $\alpha$-pineno, $\beta$-pineno, canfeno, cânfora, espatulenol, 1,8-cineol, metileugenol, $\alpha$-copaeno, E-anetol, anisaldeído, formiato de anisila (Morais et al. 2006), $\beta$-felantreno, trans- $\beta$-guaieno, E-cariofileno, cis- $\beta$-guaieno (Bertini et al. 2005) e linalol
(Angélico et al. 2011), podendo ser responsáveis pelo potencial alelopático inibitório, pois de acordo com a literatura são fitotóxicos os seguintes compostos: $\alpha$-pineno, $\beta$-pineno e canfeno (Almeida 1988; Nishida et al. 2005); cânfora, 1,8-cineol (Nishida et al. 2005); e linalol (Singh et al. 2002). Extratos voláteis de óleos essenciais de canela (Cinnamomum zeylanicum Breyn.), alecrim-pimenta (Lippia sidoides Cham.), capim-citronela (Cymbopogum citratus (DC) Stapf.) e alfavaca-cravo (Ocimum gratissimum L.) possuem monoterpenos como compostos majoritários o que já foi relacionado à sua fitotoxidez e potencial alelopático (Alves et al. 2004).

A fitotoxidez dos hidrolatos foi mais intensa no fotoperíodo de $12 \mathrm{~h}$ de luz, pois apesar de tanto no fotoperíodo de $12 \mathrm{~h}$ como no de $14 \mathrm{~h}$ de luz, quatro espécies terem inibido a germinação de alface, os valores da $1^{\mathrm{a}} \mathrm{C}$ no fotoperíodo de $12 \mathrm{~h}$ de luz são menores. Tendo em vista que a germinação da cultivar de alface estudada não é fotossensível, este resultado sugere que a maior exposição do hidrolato à luz, aumentou a sua degradação. Dentre as espécies estudadas em ambos fotoperíodos, para $1^{\text {a }} \mathrm{C}$ a de poder inibitório mais eficiente foi o C. nepetafolius na concentração de $100 \%$ de hidrolato.

Para as sementes de tomate, em todos os ensaios, a germinação do controle teve início entre 48 e 72 horas. Nos bioensaios com fotoperíodo de $12 \mathrm{~h}$ de luz foi observado na $1^{\text {a }} \mathrm{C}$ efeito fitotóxico para os hidrolatos de todas as espécies estudadas nas concentrações de 50 e $100 \%$ de hidrolato. C. nepetaefolius foi a espécie que apresentou a maior fitotoxidez inibindo completamente a germinação de tomate em ambas as concentrações testadas (Tab. 3).

No fotoperíodo de $14 \mathrm{~h}$ de luz, para a $1^{\mathrm{a}} \mathrm{C}$ foi observado efeito fitotóxico em todas as espécies de Croton utilizadas nas sementes de tomate. Os C. argyrophylloides, $C$.

Tabela 1. Efeito fitotóxico dos hidrolatos de Croton ssp. na germinação de alface com fotoperíodo de $12 \mathrm{~h}$ de luz. Média \pm desvio padrão. $0 \%$ : controle $3 \mathrm{~mL}$ de água destilada; $50 \%$ : $1,5 \mathrm{~mL}$ de hidrolato diluído em $1,5 \mathrm{~mL}$ de água destilada; $100 \%$ : $3 \mathrm{~mL}$ de hidrolato. $1^{\text {a }} \mathrm{C}$ : primeira contagem do teste-padrão de germinação. TPG: Teste-padrão de germinação. IVG: Índice de velocidade de germinação. Médias seguidas por letras iguais na coluna, dentro de cada espécie, não diferem entre si, pelo teste de Tukey, em nível de $5 \%$ de probabilidade.

\begin{tabular}{lcccc}
\hline Espécie & Concentração (\%) & $1^{\mathrm{a}} \mathrm{C}(\%)$ & TPG (\%) & IVG \\
\hline & 0 & $75 \pm 2,31 \mathrm{a}$ & $93,5 \pm 4,43 \mathrm{a}$ & $41,9 \pm 3,21 \mathrm{a}$ \\
C. argyrophylloides & 50 & $36,5 \pm 7,72 \mathrm{~b}$ & $94,5 \pm 5,74 \mathrm{a}$ & $31,10 \pm 2,83 \mathrm{~b}$ \\
& 100 & $3,5 \pm 3,42 \mathrm{c}$ & $92 \pm 2,31 \mathrm{a}$ & $22,21 \pm 2,12 \mathrm{c}$ \\
C. blanchetianus & 0 & $51 \pm 23,44 \mathrm{a}$ & $88 \pm 8,16 \mathrm{a}$ & $33,6 \pm 6,4 \mathrm{a}$ \\
& 50 & $49 \pm 10,89 \mathrm{a}$ & $94,5 \pm 3,42 \mathrm{a}$ & $34,37 \pm 3,21 \mathrm{a}$ \\
C. jacobinensis & 100 & $3 \pm 3,83 \mathrm{~b}$ & $91,5 \pm 3,42 \mathrm{a}$ & $21,08 \pm 2,77 \mathrm{~b}$ \\
& 0 & $83,5 \pm 9,15 \mathrm{a}$ & $95 \pm 3,46 \mathrm{a}$ & $44,28 \pm 2,88 \mathrm{a}$ \\
C. nepetaefolius & 50 & $77,5 \pm 5,26 \mathrm{a}$ & $94 \pm 4,32 \mathrm{a}$ & $42,52 \pm 2,24 \mathrm{a}$ \\
& 100 & $72 \pm 18,76 \mathrm{a}$ & $93,5 \pm 3,79 \mathrm{a}$ & $40,5 \pm 5,75 \mathrm{a}$ \\
C. sincorensis & 0 & $65 \pm 6,63 \mathrm{a}$ & $90 \pm 5,89 \mathrm{a}$ & $38,12 \pm 2,96 \mathrm{a}$ \\
& 50 & $11 \pm 9,02 \mathrm{~b}$ & $90 \pm 2,31 \mathrm{a}$ & $24,14 \pm 1,81 \mathrm{~b}$ \\
C. zehntneri & 100 & $2,5 \pm 3 \mathrm{~b}$ & $91,5 \pm 4,12 \mathrm{a}$ & $21,50 \pm 1,36 \mathrm{~b}$ \\
& 0 & $84,5 \pm 6,61 \mathrm{a}$ & $93 \pm 5,29 \mathrm{a}$ & $44,87 \pm 2,22 \mathrm{a}$ \\
& 50 & $84,5 \pm 6,62 \mathrm{a}$ & $96,5 \pm 5,51 \mathrm{a}$ & $44,71 \pm 2,4 \mathrm{a}$ \\
& 100 & $88 \pm 7,48 \mathrm{a}$ & $95,5 \pm 1,91 \mathrm{a}$ & $45,56 \pm 2,6 \mathrm{a}$ \\
& 0 & $62 \pm 5,16 \mathrm{a}$ & $93 \pm 4,76 \mathrm{a}$ & $38,13 \pm 1,79 \mathrm{a}$ \\
& 50 & $45 \pm 17,17 \mathrm{a}$ & $95,5 \pm 1,91 \mathrm{a}$ & $34,57 \pm 5,03 \mathrm{a}$ \\
\end{tabular}


Tabela 2. Efeito fitotóxico dos hidrolatos de Croton ssp. na germinação de alface com fotoperíodo de $14 \mathrm{~h}$ de luz. Média \pm desvio padrão. $0 \%$ : controle $3 \mathrm{~mL}$ de água destilada; $50 \%$ : $1,5 \mathrm{~mL}$ de hidrolato diluído em $1,5 \mathrm{~mL}$ de água destilada; $100 \%$ : $3 \mathrm{~mL}$ de hidrolato. $1^{\mathrm{a}} \mathrm{C}$ : primeira contagem do teste-padrão de germinação. TPG: Teste-padrão de germinação. IVG: Índice de velocidade de germinação. Médias seguidas por letras iguais na coluna, dentro de cada espécie, não diferem entre si, pelo teste de Tukey, em nível de $5 \%$ de probabilidade.

\begin{tabular}{lcccc}
\hline Espécie & Concentração (\%) & $1^{\mathrm{a}} \mathrm{C}(\%)$ & TPG (\%) & IVG \\
\hline & 0 & $42 \pm 9,38 \mathrm{a}$ & $87 \pm 5,29 \mathrm{a}$ & $31,8 \pm 6,07 \mathrm{a}$ \\
C. argyrophylloides & 50 & $52 \pm 11,78 \mathrm{a}$ & $94 \pm 5,41 \mathrm{~b}$ & $35,12 \pm 3,29 \mathrm{~b}$ \\
& 100 & $22 \pm 4,9 \mathrm{~b}$ & $95,5 \pm 1,91 \mathrm{~b}$ & $28,16 \pm 1,64 \mathrm{a}$ \\
C. blanchetianus & 0 & $76 \pm 6 \mathrm{a}$ & $92 \pm 4,32 \mathrm{a}$ & $41,29 \pm 1,74 \mathrm{a}$ \\
& 50 & $67,5 \pm 8,85 \mathrm{a}$ & $91,5 \pm 3,42 \mathrm{a}$ & $36,77 \pm 6,19 \mathrm{a}$ \\
C. jacobinensis & 100 & $19 \pm 11,24 \mathrm{~b}$ & $93 \pm 3,46 \mathrm{a}$ & $27,24 \pm 4,24 \mathrm{~b}$ \\
& 0 & $85 \pm 5,29 \mathrm{a}$ & $95,5 \pm 1,91 \mathrm{a}$ & $44,92 \pm 1,85 \mathrm{a}$ \\
C. nepetaefolius & 50 & $85 \pm 7,75 \mathrm{ab}$ & $95,5 \pm 2,52 \mathrm{a}$ & $44,72 \pm 2,93 \mathrm{a}$ \\
& 100 & $74,5 \pm 11 \mathrm{~b}$ & $95,5 \pm 3,41 \mathrm{a}$ & $41,75 \pm 3,52 \mathrm{a}$ \\
C. sincorensis & 0 & $76,5 \pm 6,19 \mathrm{a}$ & $95 \pm 4,76 \mathrm{a}$ & $42,38 \pm 2,41 \mathrm{a}$ \\
& 50 & $51,5 \pm 5 \mathrm{~b}$ & $91,5 \pm 2,52 \mathrm{a}$ & $34,86 \pm 3,57 \mathrm{~b}$ \\
C. zehntneri & 100 & $3,5 \pm 3 \mathrm{c}$ & $81,5 \pm 5,97 \mathrm{~b}$ & $19,73 \pm 1,67 \mathrm{c}$ \\
& 0 & $66,5 \pm 11,24 \mathrm{a}$ & $91,5 \pm 3 \mathrm{a}$ & $38,54 \pm 3,71 \mathrm{a}$ \\
& 50 & $85,5 \pm 4,43 \mathrm{~b}$ & $95,5 \pm 1,91 \mathrm{a}$ & $44,84 \pm 1,41 \mathrm{~b}$ \\
& 100 & $85 \pm 7,75 \mathrm{~b}$ & $94 \pm 3,27 \mathrm{a}$ & $44,34 \pm 2,81 \mathrm{~b}$ \\
\hline
\end{tabular}

Tabela 3. Efeito fitotóxico dos hidrolatos de Croton ssp. na germinação de tomate com fotoperíodo de $12 \mathrm{~h}$ de luz. Média \pm desvio padrão. $0 \%$ : controle $3 \mathrm{~mL}$ de água destilada; $50 \%$ : $1,5 \mathrm{~mL}$ de hidrolato diluído em $1,5 \mathrm{~mL}$ de água destilada; $100 \%$ : $3 \mathrm{~mL}$ de hidrolato. $1^{\mathrm{a}} \mathrm{C}$ : primeira contagem do teste-padrão de germinação. TPG: Teste-padrão de germinação. IVG: Índice de velocidade de germinação. Médias seguidas por letras iguais na coluna, dentro de cada espécie, não diferem entre si, pelo teste de Tukey, em nível de $5 \%$ de probabilidade.

\begin{tabular}{|c|c|c|c|c|}
\hline Espécie & Concentração (\%) & $1^{\mathrm{a}} \mathrm{C}(\%)$ & TPG $(\%)$ & IVG \\
\hline \multirow{3}{*}{ C. argyrophylloides } & 0 & $53 \pm 19,76 \mathrm{a}$ & $88,5 \pm 9,98 \mathrm{a}$ & $10,13 \pm 1,58 \mathrm{a}$ \\
\hline & 50 & $17,5 \pm 9,71 \mathrm{~b}$ & $94 \pm 2,83 \mathrm{a}$ & $9,61 \pm 0,4 \mathrm{a}$ \\
\hline & 100 & $4,5 \pm 5,26 \mathrm{~b}$ & $83 \pm 9,45 \mathrm{a}$ & $7,67 \pm 0,98 \mathrm{~b}$ \\
\hline \multirow{3}{*}{ C. blanchetianus } & 0 & $41,5 \pm 16,52 \mathrm{a}$ & $97 \pm 1,15 \mathrm{a}$ & $10,76 \pm 0,51 \mathrm{a}$ \\
\hline & 50 & $1 \pm 2 b$ & $69 \pm 14,09 \mathrm{~b}$ & $5,96 \pm 1,35 \mathrm{~b}$ \\
\hline & 100 & $1 \pm 2 b$ & $66 \pm 12,75 \mathrm{~b}$ & $5,7 \pm 1,16 \mathrm{~b}$ \\
\hline \multirow{3}{*}{ C. jacobinensis } & 0 & $70,5 \pm 5,74 \mathrm{a}$ & $95,5 \pm 2,52 \mathrm{a}$ & $14,42 \pm 0,68 \mathrm{a}$ \\
\hline & 50 & $15 \pm 4,16 \mathrm{~b}$ & $90,5 \pm 5,26 \mathrm{a}$ & $11,25 \pm 0,9 \mathrm{~b}$ \\
\hline & 100 & $1 \pm 1,15 \mathrm{c}$ & $82 \pm 5,89 \mathrm{~b}$ & $8,47 \pm 0,79 \mathrm{c}$ \\
\hline \multirow{3}{*}{ C. nepetaefolius } & 0 & $30,5 \pm 7,19 \mathrm{a}$ & $97 \pm 3,83 \mathrm{a}$ & $10,35 \pm 0,55 \mathrm{a}$ \\
\hline & 50 & $0 \mathrm{~b}$ & $3 \pm 3,83 \mathrm{~b}$ & $0,25 \pm 0,32 \mathrm{~b}$ \\
\hline & 100 & $0 \mathrm{~b}$ & $0 \mathrm{~b}$ & $0 \mathrm{~b}$ \\
\hline \multirow{3}{*}{ C. sincorensis } & 0 & $90,5 \pm 4,43 \mathrm{a}$ & $99 \pm 1,15 \mathrm{a}$ & $16,77 \pm 0,38 \mathrm{a}$ \\
\hline & 50 & $47,5 \pm 6,4 \mathrm{~b}$ & $94 \pm 3,65 b$ & $13,05 \pm 0,33 \mathrm{~b}$ \\
\hline & 100 & $12 \pm 5,16 \mathrm{c}$ & $85,5 \pm 4,43 \mathrm{c}$ & $9,8 \pm 1,08 \mathrm{c}$ \\
\hline \multirow{3}{*}{ C. zehntneri } & 0 & $75,5 \pm 10,5 \mathrm{a}$ & $98,5 \pm 1,9 \mathrm{a}$ & $15,68 \pm 0,95 \mathrm{a}$ \\
\hline & 50 & $2 \pm 2,82 \mathrm{~b}$ & $95 \pm 1,1 \mathrm{~b}$ & $11,50 \pm 0,27 \mathrm{~b}$ \\
\hline & 100 & $3 \pm 3,83 \mathrm{~b}$ & $96 \pm 2,8 \mathrm{ab}$ & $11,56 \pm 0,66 \mathrm{~b}$ \\
\hline
\end{tabular}

blanchetianus, C. nepetaefolius e C. zehntneri inibiram a germinação nas concentrações de 50 e $100 \%$ em relação ao controle. O C.jacobinensis e o C. sincorensis obtiveram essa mesma inibição apenas na concentração de 100\%. Para $1^{\text {a }} \mathrm{C}$, o $C$. nepetaefolius foi a espécie que apresentou o maior potencial inibitório, com as concentrações de 50 e $100 \%$, tendo $0 \%$ de germinação (Tab. 4).

Para $1^{\mathrm{a}} \mathrm{C}$, a ação fitotóxica nas sementes de tomate foi eficiente, pois todos os hidrolatos apresentaram fitotoxidez, portanto, a semente de tomate é sensível a estes. Os resultados sugerem que o poder inibitório dos hidrolatos foi mais eficientes no fotoperíodo de $12 \mathrm{~h}$ de luz, pois retardou a germinação, resultando nos menores valores da $1^{\mathrm{a}} \mathrm{C}$.

C. sincorensis demonstrou fitotoxidez na $1^{\mathrm{a}} \mathrm{C}$ somente em sementes de tomate e ação estimulante apenas para alface. Desta forma, é possível que os constituintes voláteis presentes neste hidrolato não sejam fitotóxicos para essa espécie receptora. Porém foram fitotóxicos para tomate. Estudos semelhantes feitos por Alves et al. (2004) demonstraram que o óleo de Pilocarpus microphyllus Stapf. ex. Wardleworth (jaborandi) possui efeito alelopático 
Tabela 4. Efeito fitotóxico dos hidrolatos de Croton ssp. na germinação de tomate com fotoperíodo de 14 h de luz. Média \pm desvio padrão. $0 \%$ : controle $3 \mathrm{~mL}$ de água destilada; $50 \%: 1,5 \mathrm{~mL}$ de hidrolato diluído em 1,5 mL de água destilada; $100 \%: 3 \mathrm{~mL}$ de hidrolato. $1^{\text {a }} \mathrm{C}$ : primeira contagem do teste-padrão de germinação. TPG: Teste-padrão de germinação. IVG: Índice de velocidade de germinação. Médias seguidas por letras iguais na coluna, dentro de cada espécie, não diferem entre si, pelo teste de Tukey, em nível de 5\% de probabilidade.

\begin{tabular}{|c|c|c|c|c|}
\hline Espécie & Concentração (\%) & $1^{\mathrm{a}} \mathrm{C}(\%)$ & TPG (\%) & IVG \\
\hline \multirow{3}{*}{ C. argyrophylloides } & 0 & $68,5 \pm 13,8 \mathrm{a}$ & $91 \pm 15,36 \mathrm{a}$ & $14,55 \pm 1,47 \mathrm{a}$ \\
\hline & 50 & $10 \pm 2,83 b$ & $95,5 \pm 2,52 \mathrm{a}$ & $12,27 \pm 0,37 \mathrm{a}$ \\
\hline & 100 & $1 \pm 1,15 \mathrm{c}$ & $98 \pm 2,83 \mathrm{a}$ & $11,67 \pm 0,67 \mathrm{a}$ \\
\hline \multirow{3}{*}{ C. blanchetianus } & 0 & $26 \pm 10,58 \mathrm{a}$ & $92 \pm 9,38 \mathrm{a}$ & $12,52 \pm 1,5 \mathrm{a}$ \\
\hline & 50 & $0 \mathrm{~b}$ & $95,5 \pm 3,42 \mathrm{a}$ & $11,53 \pm 0,62 \mathrm{a}$ \\
\hline & 100 & $1,5 \pm 1,91 \mathrm{ab}$ & $97 \pm 2 \mathrm{a}$ & $11,35 \pm 0,25 \mathrm{a}$ \\
\hline \multirow{3}{*}{ C. jacobinensis } & 0 & $91 \pm 2,58 \mathrm{a}$ & $97 \pm 2,58 \mathrm{a}$ & $16,36 \pm 0,52 \mathrm{a}$ \\
\hline & 50 & $83 \pm 15,36 \mathrm{a}$ & $97,5 \pm 3,79 \mathrm{a}$ & $15,58 \pm 1,1 \mathrm{ab}$ \\
\hline & 100 & $55 \pm 5,29 b$ & $95,5 \pm 5,26 \mathrm{a}$ & $14,28 \pm 0,19 b$ \\
\hline \multirow{3}{*}{ C. nepetaefolius } & 0 & $65 \pm 10,52 \mathrm{a}$ & $95 \pm 2,58 \mathrm{a}$ & $14,58 \pm 0,52 \mathrm{a}$ \\
\hline & 50 & $0 \mathrm{~b}$ & $78 \pm 11,66 \mathrm{ab}$ & $5,84 \pm 3,48 \mathrm{ab}$ \\
\hline & 100 & $0 \mathrm{~b}$ & $4,5 \pm 4,12 b$ & $0,38 \pm 0,34 b$ \\
\hline \multirow{3}{*}{ C. sincorensis } & 0 & $82,5 \pm 5 \mathrm{a}$ & $95 \pm 4,76 \mathrm{a}$ & $16,75 \pm 1,44 \mathrm{a}$ \\
\hline & 50 & $76,5 \pm 7,72 \mathrm{a}$ & $97 \pm 1,15 \mathrm{a}$ & $15,29 \pm 0,37 b$ \\
\hline & 100 & $59,5 \pm 5,51 \mathrm{~b}$ & $94,5 \pm 3,41 \mathrm{a}$ & $14,03 \pm 0,65 b$ \\
\hline \multirow{3}{*}{ C. zehntneri } & 0 & $88 \pm 5,89 a$ & $97,5 \pm 1,91 \mathrm{a}$ & $16,03 \pm 0,28 \mathrm{a}$ \\
\hline & 50 & $64 \pm 10,46 b$ & $97 \pm 1,15 \mathrm{a}$ & $14,73 \pm 0,4 \mathrm{ab}$ \\
\hline & 100 & $22 \pm 2,83 \mathrm{c}$ & $95,5 \pm 1,91 \mathrm{a}$ & $13,33 \pm 1,08 b$ \\
\hline
\end{tabular}

benéfico, pois estimula o crescimento da radícula e não provoca inibição da germinação de alface. Mazzafera (2003) estudou extratos de S. aromaticum que apresentaram ação alelopática mais evidente em sementes de tomate que em diásporos de alface, indicando uma sensibilidade maior da semente de tomate. Por outro lado, Lima \& Morais (2008) encontraram uma maior sensibilidade à inibição na alface do que no tomate provocada por extrato de folhas de Ipomoea fistulosa Mart. ex Choisy.

\section{Teste-padrão de germinação (TPG)}

Os diásporos de alface postos para germinar em $12 \mathrm{~h}$ de luz não apresentaram diferença estatística quanto ao teste-padrão de germinação (TPG) (Tab. 1). Por outro lado, no fotoperíodo de $14 \mathrm{~h}$ de luz os resultados dos TPGs apresentaram diferença estatística no C. nepetaefolius demonstrando seu efeito fitotóxico e no C. argyrophylloides que proporcionou uma maior porcentagem de germinação, demonstrando o seu efeito estimulante (Tab. 2). Em trabalho realizado com Croton urucurana Baill., também foi verificado efeito fitotóxico na germinação de alface, sendo observada inibição no crescimento de alface em $100 \%$, em comparação ao controle, quando submetidas ao óleo volátil do caule de C. urucurana (Simionatto et al. 2009).

As sementes de tomate postas para germinar em $12 \mathrm{~h}$ de luz apresentaram diferença estatística quanto ao TPG, com exceção do C. argyrophylloides. A espécie C. nepetaefolius foi a que apresentou o mais duradouro potencial inibitório, com a concentração de $100 \%$, tendo $0 \%$ de germinação até mesmo após 144 h (Tab. 3). Já no fotoperíodo de 14 $\mathrm{h}$ de luz apenas o $C$. nepetaefolius apresentou diferença estatística. A espécie $C$. nepetaefolius apresentou o maior e mais duradouro potencial inibitório, com a concentração de $100 \%$ germinando apenas após 144 h, com 4,5 $\pm 4,12 \%$ de germinação (Tab. 4).

A ausência de diferença estatística nos TPGs de alface no fotoperíodo de $12 \mathrm{~h}$ de luz é explicado por Ferreira \& Aquila (2000), ao afirmarem que muitas vezes, o que se observa são efeitos significativos de extratos sobre o tempo médio e entropia de germinação, no entanto, nenhuma diferença é observada na germinabilidade total.

\section{Índice de velocidade de germinação (IVG)}

Em diásporos de alface o índice de velocidade de germinação (IVG) em 12 h de luz apresentou fitotoxidez em C. argyrophylloides, C. blanchetianus, C. nepetaefolius e C. zehntneri. Os hidrolatos de C. argyrophylloides e C. nepetaefolius apresentaram diferença estatística nas concentrações de 50 e $100 \%$, já os C. blanchetianus e C. zehntneri apresentaram apenas na concentração de $100 \%$ (Tab. 1). No fotoperíodo $14 \mathrm{~h}$ de luz as espécies $C$. argyrophylloides, C. blanchetianus, $C$. nepetaefolius e $C$. sincorensis apresentaram diferença estatística. Porém, os $C$. blanchetianus e $C$. nepetaefolius apresentaram fitotoxidez com seus IVGs inferiores ao controle, enquanto o $C$. argyrophylloides e $C$. sincorensis apresentam uma atividade estimulante com seu IVG superior ao controle (Tab. 2).

Em sementes de tomate o IVG em $12 \mathrm{~h}$ de luz apresentou diferença estatística em todas as espécies, demonstrando a fitotoxidez de todos os hidrolatos. O C. nepetaefolius possui a maior fitotoxidez, enquanto o C. zehntneri possui a menor fitotoxidez, ambos apresentando os menores IVGs nas concentrações de 50 e $100 \%$ (Tab. 3). No fotoperíodo $14 \mathrm{~h}$ de luz o IVG apenas em $C$. argyrophylloides e $C$. blanchetianus não apresentaram diferença estatística, todas as outras espécies apresentaram fitotoxidez. Os resultados sugerem que o C. nepetaefolius possui a maior fitotoxidez, 
apresentando o menor IVG na concentração de 100\% (Tab. 4).

Os monoterpenos e sesquiterpenos presentes nas espécies de Croton (Morais et al. 2006) provocam fitotoxidez para o IVG de tomate semelhantes ao do estudo de Rosado (2009) com extrato aquoso de manjericão (Ocimum basilicum L.), que também tem compostos monoterpenos e sesquiterpenos tais como: 1,8-cineol, linalol, $\alpha$-terpineol, geraniol, acetato de geranila, $\alpha$-trans-bergamoteno, $\gamma$-cadineno e epi- $\alpha$ cadinol; sendo o monoterpeno linalol, também presente no Croton, o composto majoritário (78,35\%), portanto, o possível responsável pelos efeitos fitótoxicos.

A mais alta fitotoxidez do C. nepetaefolius pode estar relacionada a produção do metil-eugenol, um dos constituintes de seu óleo essencial que pode estar presente no seu hidrolato (Morais et al. 2006). Semelhante as folhas de Syzygium aromaticum, que são fontes natural de derivados do eugenol, e apresentam fitotoxidez no extrato alcoólico (Mazzafera 2003).

Todos os hidrolatos demonstraram algum grau de fitotoxidez, inibindo a germinação de alface e de tomate. As ações inibitórias dos hidrolatos de Croton foram mais eficientes no fotoperíodo de $12 \mathrm{~h}$ de luz e na concentração $100 \%$.

Os dados sugerem que o hidrolato de C. nepetaefolius possui a fitotoxidez mais alta dentre as espécies do estudo, e os hidrolatos de C. sincorensis e C. argyrophylloides apresentaram efeito estimulante.

\section{REFERÊNCIAS}

Almeida, F.S. 1988. A alelopatia e as plantas. Instituto Agronômico do Paraná, Londrina. 60p.

Alves, M.C.S., Medeiros-Filho, S., Innecco, R. \& Torres, S.B. 2004. Alelopatia de extratos voláteis na germinação de sementes e no comprimento da raiz de alface. Pesquisa Agropecuária Brasileira 39(11):1083-1086.

Angélico, E.C., Costa, J.G.M., Rodrigues, O.G., Lima, E.Q. \& Medeiros, R.S. 2011. Revista de Biologia e Farmácia 5(2): 44-49.

Bertini, L.M., Pereira, A.F., Oliveira, C.L.L. de, Menezes, E.A., Morais, S.M. de, Cunha, F.A. \& Cavalcanti, E.S.B. 2005. Perfil de sensibilidade de bactérias frente a óleos essenciais de algumas plantas do Nordeste do Brasil. Infarma 17(3/4): 80-83.

Borba, A.M. \& Macedo, M. 2006. Plantas medicinais usadas para a saúde bucal pela comunidade do bairro Santa Cruz, Chapada dos Guimarães, MT, Brasil. Acta Botanica Brasilica 20(4):771-782.

Brasil. 2009. Regras para análise de sementes. Ministério da Agricultura, Pecuária e Abastecimento, Brasília. 399 p.

Carvalho, G.J., Andrade, L.A.B., Gomide, M. \& Figueiredo, P.A.M. 1996. Potencialidades alelopáticas de folhas verdes mais ponteiro de cana-de-açúcar em diferentes concentrações de matéria seca, na germinação de sementes de alface. Ciências 5(2): 19-24.

Cordeiro, I., Secco, R., Carneiro-Torres, D.S., Lima, L.R. de, Caruzo, M.B.R., Berry, P., Riina, R., Silva, O.L.M., Silva, M.J. \& Sodré, R.C. 2015. Cróton. In Lista de Espécies da Flora do Brasil. Jardim
Botânico do Rio de Janeiro. Disponível em: http://reflora.jbrj.gov. br/jabot/floradobrasil/FB17497. Acessado em 03.02.2015.

Cruz, M.E.S., Nozaki, M.H. \& Batista, M.A. 2000. Plantas Medicinais: Plantas medicinais e alelopatia. Biotecnologia Ciência e Desenvolvimento 15: 28-34.

Cunha, A.P., Nogueira, M.T. \& Roque, O.R. 2012. Plantas aromáticas e óleos essenciais: composição e aplicações. Fundação Calouste Gulbenkian, Lisboa. 678 p.

Ferreira, G.A. \& Aquila, M.E.A. 2000. Alelopatia: uma área emergente da ecofisiologia. Revista Brasileira de Fisiologia Vegetal 12: 175-204.

Instituto Nacional de Meteorologia. INMET. 2014. Disponível em: http:// www.inmet.gov.br/portal/. Acessado em 01.07.2014.

Labouriau, L.G. \& Valadares, M.E.B. 1976. On the germination of seeds of Calotropis procera (Ait.) Ait.f. Anais da Academia Brasileira de Ciências 48(2): 263-284.

Lavabre, M. 1993. Aromaterapia: a cura pelos óleos essenciais. Record, Rio de Janeiro. $172 \mathrm{p}$.

Lima, J.D. \& Morais, W.S. 2008. Potencial alelopático de Ipomoea fistulosa sobre a germinação de alface e tomate. Acta Scientiarum. Agronomy 30(3): 409-413.

Lima, M.G.A., Maia, I.C.C., Souza, B.D., Morais S.M. \& Freitas, S.M. 2006. Effect of stalk and leaf extracts from Euphorbiaceae species on Aedes aegypti (Diptera, Culicidae) larvae. Revista do Instituto de Medicina Tropical de São Paulo 48(4): 211-214.

Mazzafera, P. 2003. Efeito alelopático do extrato alcoólico do cravoda-índia e eugenol. Revista Brasileira de Botânica 26(2): 231-238.

Morais, S.M., Catunda-Junior, F.E.A., Silva, A.R.A. \& Martins-Neto, J.S. 2006. Atividade antioxidante de óleos essenciais de espécies de Croton do nordeste do Brasil. Química Nova 29(5): 907-910.

Moura, G.S., Franzener, G., Stangarlin, J.R. \& Schwan-Estrada, K.R.F. 2014. Atividade antimicrobiana e indutora de fitoalexinas do hidrolato de carqueja [Baccharis trimera (Less.) DC.]. Revista Brasileira de Plantas Medicinais 16(2): 309-315.

Müller, C., Chagas, F.F., Peres, M.T.L.P., Hess, S.C., Faccenda, O. \& Daloso, D.M. 2007. Potencial Fitotóxico de Algumas Espécies Gleicheniaceae sobre Allium cepa L. Revista Brasileira de Biociências 5(2): 45-47.

Nishida, N., Tamotsu, S., Nagata, N., Saito, C. \& Sakai, A. 2005. Allelopathic effects of volatile monoterpenoids produced by Salvia leucophylla: inhibition of cell proliferation and DNA synthesis in the root apical meristem of Brassica campestris seedlings. Journal of Chemical Ecology 31(5): 1187-1203.

Ribeiro, R.C., de Carvalho, M.G., Lopes, H.M., Rossiello, R.O.P. \& Barbieri Junior, É. 2012. Allelopathic activity of the hydrolate and water decoction of Brachiaria humidicola (Rendle) plant parts on the germination of four tropical leguminous species. International Scholarly Research Notices, p. 1-6.

Rosado, L.D.S., Rodrigues, H.C.A., Pinto, J.E.B.P., Custódio, T.N., Pinto, L.B.B. \& Bertolucci, S.K.V. 2009. Alelopatia do extrato aquoso e do óleo essencial de folhas do manjericão "Maria Bonita" na germinação de alface, tomate e melissa. Revista Brasileira de Plantas Medicinais 11(4): 422-428.

Simionatto, E., Bonani, V.F., Peres, M.T., Hess, S.C., Candido, A.C., Diraimo, D.L., Poppi, N.R., Matos, M.F.C., Santos, E.C.S., Oguma, P.M. \& de Carvalho, J.E. 2009. Bioactivity and chemical composition of the essential oils of Croton urucurana Baillon (Euphorbiaceae). Journal of Essential Oil Bearing Plants 12(3): 250-261.

Singh, H.P., Batish, D.R., Kaur, S., Ramezani, H. \& Kohli, R.K. 2002. Comparative phytotoxicity of four monoterpenes against Cassia occidentalis. Annals of Applied Biology 141(2): 111-116.

Vieira, R.D. \& Carvalho, N.M. 1994. Teste de vigor em sementes. Fundação de Apoio a Pesquisa, Ensino e Extensão, Universidade Estadual Paulista, Faculdade de Ciências Agrárias e Veterinárias, Jaboticabal. $164 \mathrm{p}$. 